\title{
Structural Evolution of Silica Sols Modified with Formamide
}

\author{
R.F.S. Lenza ${ }^{\#}$, W.L. Vasconcelos* \\ Federal University of Minas Gerais - Department of Metallurgical and Materials \\ Engineering, 30160-030 Belo Horizonte - MG, Brazil
}

Received: November 21, 2000; Revised: June 28, 2001

\begin{abstract}
In this work we investigated the influence of formamide on the acid-catalyzed sol-gel process by Fourier transform infrared spectroscopy (FTIR). Three silica sols were studied: Sol catalyzed with nitric acid without formamide, sol catalyzed with nitric acid containing formamide and sol catalyzed with a mixture of nitric acid and hydrofluoric acid and modified with formamide. Following the time evolution of both the $\mathrm{Si}-(\mathrm{OH})$ stretching vibration at around $950 \mathrm{~cm}^{-1}$ and the $\mathrm{Si}-\mathrm{O}-(\mathrm{Si})$ vibration between $1040 \mathrm{~cm}^{-1}$ and $1200 \mathrm{~cm}^{-1}$ we were able to describe the structural evolution of each sol. The curve of evolution of $\mathrm{Si}-(\mathrm{OH})$ stretching vibration corresponding to sol A has a simple asymptotic evolution. In the case of formamide containing sol, we observed a two-step structural evolution indicating that for the system containing formamide the polymerization goes through a temporary stabilization of oligomers, which can explain the non-variation of the $\mathrm{Si}-\mathrm{O}(\mathrm{H})$ bond wavenumber for a certain time. Gelation times were of several days for gels without formamide and few hours for gels containing additive. The presence of additive resulted in a highly interconnected gel.
\end{abstract}

Keyworks: sol-gel, formamide, FTIR, structural evolution

\section{Introduction}

Sol gel is a low temperature method using chemical precursors that produces ceramics and glasses with better purity and homogeneity than high temperature conventional processes. Sol gel has produced a wide range of compositions (mostly oxides) in various forms, including powders, fibers, coatings and thin films, monoliths and composites, and porous membranes ${ }^{1-3}$.

The sol-gel process of silica involves the hydrolysis (1) and condensation $(2,3)$ of alkoxides, such as tetraethoxysilane or tetramethoxysilane. These monosilanes form on these reactions (1-3) many different linear, branched and cyclic intermediates ${ }^{1,4}$.

$$
\begin{aligned}
& \equiv \mathrm{Si}-\mathrm{OR}+\mathrm{H}_{2} \mathrm{O} \rightarrow \equiv \mathrm{Si}-\mathrm{OH}+\mathrm{ROH} \\
& \equiv \mathrm{Si}-\mathrm{OR}+\mathrm{HO}-\mathrm{Si} \equiv \rightarrow \equiv \mathrm{Si}-\mathrm{O}-\mathrm{Si} \equiv+\mathrm{ROH} \\
& \equiv \mathrm{Si}-\mathrm{OH}+\mathrm{HO}-\mathrm{Si} \equiv \rightarrow \equiv \mathrm{Si}-\mathrm{O}-\mathrm{Si} \equiv+\mathrm{H}_{2} \mathrm{O}
\end{aligned}
$$

By controlling the synthesis conditions carefully, sol morphology can be directed towards branched polymeric systems or to particulate systems ${ }^{2}$. Control of relative rates of hydrolysis and polycondensation, and the respective

*e-mail:wlv@demet.ufmg.br

\# e-mail: rulenza@ zipmail.com.br

Trabalho apresentado no $14^{\circ} \mathrm{CBECIMAT,} \mathrm{Águas} \mathrm{de} \mathrm{São} \mathrm{Pedro,} \mathrm{Dezem-}$ bro de 2000 . mechanisms of these reactions are the main tools for this difference ${ }^{1,2,5-7}$.

A great deal of effort has been devoted to improve the understanding of the various stages of the sol-gel process. It has been shown that besides $\mathrm{pH}$, temperature of process, pressure, solvent, concentration of alkoxide, type and concentration of catalysts and DCCA (Drying Control Chemical Additive) play an important role in determining morphology of the resulting polymeric structure ${ }^{1,2,4}$. Besides the possibility of modifying the hydrolysis and polycondensation reactions, it is now well known that addition of DCCA to a mixture of alkoxide, water and alcohol, improves the processing control of gels structure and processability $^{5,8}$. Formamide is a typical DCCA. Using this additive it is then possible to dry gels directly in an open container avoiding the cracking process. However, a systematic study and a molecular level understanding of the effect of formamide and other additives is still lacking ${ }^{4,9}$, and the knowledge of their behavior is necessary to understand the reaction path of the technical process and opens a way to control properties of the resulting materials.

Numerous techniques have been employed in the study of sol to gel evolution, such as ${ }^{29} \mathrm{SiNMR}^{9,10}$, Raman Spec- 
troscopy ${ }^{11}$ and SAXS ${ }^{2}$. Among these methods, infrared spectroscopy has proven to be a very successful technique to follow the gelation process in silicate system ${ }^{1,7,8}$.

In the present study we shall investigate the effect of formamide on the gelation process of three different silica-gel systems by Fourier transform infrared spectroscopy (FTIR). Some important conclusions are made concerning the structural evolution of the sols. The results obtained are also compared with aggregation models from literature.

\section{Experimental Procedure}

Polymeric silica sols were prepared by hydrolysis and condensation of tetraethoxysilane $\left(\mathrm{Si}(\mathrm{OEt})_{4}, \mathrm{TEOS}\right.$, Aldrich, Co.) in alcohol (ethanol, Merck, Co.). As catalyst we used nitric acid (Merck, Co.). The molar ratios $\mathrm{TEOS} / \mathrm{H}_{2} \mathrm{O} / \mathrm{EtOH} / \mathrm{HNO}_{3}$ used were $1 / 10 / 6 / 0.085$. In order to study the effect of formamide as additive in the sol-gel process, three systems were prepared: Sol A was prepared without formamide; sols $\mathrm{B}$ and $\mathrm{C}$ were prepared with a molar ratio formamide/TEOS equal to 1 . Sol $\mathrm{C}$ also contains a $0,5 \mathrm{~mol} / \mathrm{L}$ of Hydrofluoric acid (Merck, Co.).

TEOS was carefully added to a mixture of water, acid and alcohol under vigorous stirring at $40{ }^{\circ} \mathrm{C}$. Thus, an appropriate amount of formamide was added. In order to evaluate the influence of this additive on the gelation time and some structural properties of the gels obtained, sols were cast into plastic tubes after $30 \mathrm{~min}$ of mixture and gelled at room temperature and at $40{ }^{\circ} \mathrm{C}$. The samples were keept in closed containers during gelation. The $\mathrm{pHs}$ of sols were measured by pHmeter Chemcadet 5986-50 of Cole Parmer Co. at intervals of $10 \mathrm{~min}$.

The sols evolution was monitored in situ by FTIR spectroscopy by means of ATR mode (Attenuated Total Reflection). FTIR spectroscopy was performed using a FTIR Paragon-1000 of Perkin Elmer Co. with a triglyceride sulfate detector. $100 \mu \mathrm{L}$ of sols were pressed against a KRS-5 crystal and FTIR spectra were collected with a $4 \mathrm{~cm}^{-1}$ resolution. Typically, 64 scans were accumulated for each spectrum, in the frequency range of $4000 \mathrm{~cm}^{-1}$ to $600 \mathrm{~cm}^{-1}$. Spectra were successively recorded from $1 \mathrm{~min}$ after addition of formamide up to fewer minutes before gelation, since after this point the spectra were poorly resolved by this technique. The solutions were maintained at $40{ }^{\circ} \mathrm{C}$ in closed containers under constant stirring. Spectral manipulations such as smoothing, baseline adjustment, normalization and peak deconvolution were performed. Voight function was used throughout and peak fitting was carried out until squared correlation coefficients with $\mathrm{r}^{2}$ greater than 0.995 were obtained. Specific surface areas and pore volumes of the samples were measured by nitrogen adsorption (Autosorb 1, Quantachrome, Co.). Prior to $\mathrm{N}_{2}$ sorption, samples were degassed at $100{ }^{\circ} \mathrm{C}$ for $12 \mathrm{~h}$ to remove physically adsorbed material from their surfaces. The specific surface areas were determined using BET plots ${ }^{1}$.

\section{Results}

Figure 1 presents the spectra of pure TEOS and spectra of sols after $1 \mathrm{~min}$ of reaction. We observed, through the bands centered on $1167 \mathrm{~cm}^{-1}$ and $784 \mathrm{~cm}^{-1}$ associated to vibration of $\mathrm{Si}-\mathrm{O}\left(\mathrm{C}_{2} \mathrm{H}_{5}\right)$ group, that hydrolysis is not complete after this time. It was observed in the spectrum of sol A that after 3 min of reaction no band due to alkoxide was present. On the other hand, spectra of sols B and C showed that the hydrolysis was not completed after 3 min of reaction.

Figure 2 shows spectra of sols after 5 min of reaction. One can observe that no band due to unhydrolyzed TEOS is present. Thus, we conclude that the hydrolysis reaction goes to completion in the early stage of the process. All the spectra present the same characteristic bands of silica-gel system, with exception of a strong band at about $1690 \mathrm{~cm}^{-1}$ characteristic of a $\mathrm{C}=\mathrm{O}$ bond belonging to formate or amide groups, present in the spectra of sols containing formamide ${ }^{7}$.

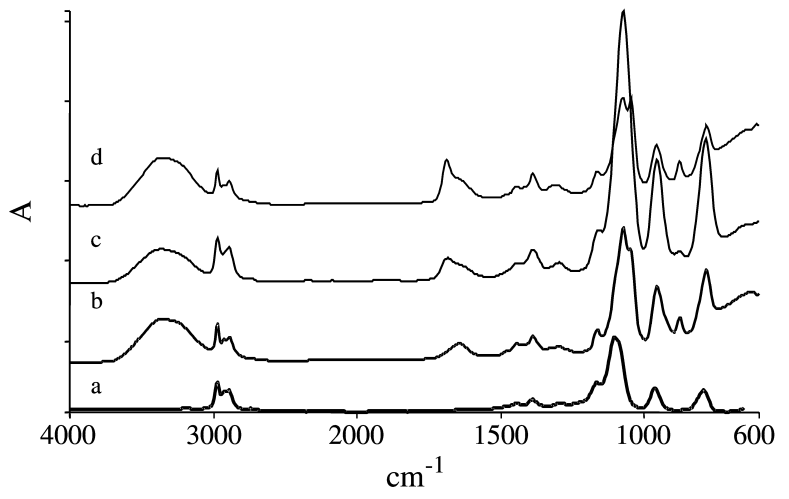

Figure 1. Spectra of pure TEOS (a) and sols A (b); B (c) and C (d) after 1 min of reaction.

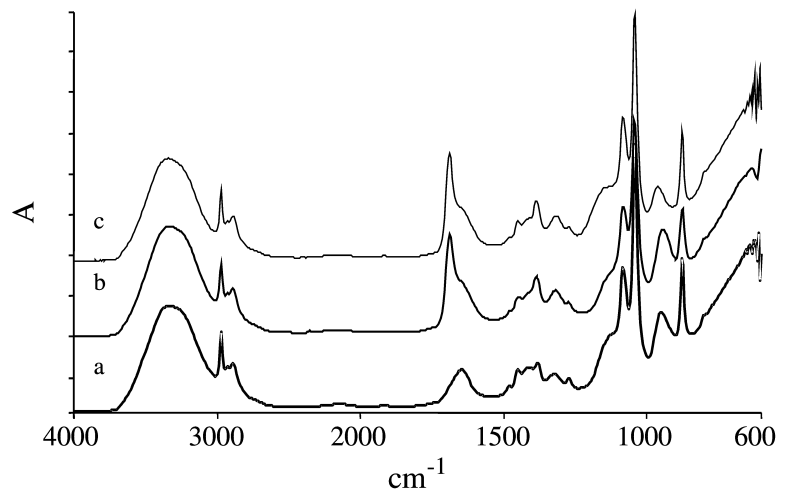

Figure 2. Spectra of sols A (b); B (c) and C (c) after 5 min of reaction. 
Formamide has a drastic effect on the hydrolysis of sol-gel systems. Compared to using only ethanol as a solvent, formamide causes a reduction in the hydrolysis rate, based on the disappearance of bands due to alkoxide. The effect of formamide was generally explained on the basis of hydrogen bonding and solvent viscosity. Although both ethanol and formamide exhibits higher values of both $\varepsilon$, dielectric constant and $\mu$, dipole moment, these values are larger to formamide ( $\varepsilon=110$ and $24.3, \mu=3.7$ and 1.69 for formamide and ethanol, respectively) and is therefore expected that formamide to hydrogen bond more strongly to protons under acidic conditions, reducing the effective catalyst activity. In addition, the viscosity of formamide is approximately seven times greater than for ethanol, at $25{ }^{\circ} \mathrm{C}$. It was postulated that the increased viscosity may reduce the ability of the nucleus to reorient during hydrolysis reaction and reducing also the diffusion coefficients of reactive species within the solution, further reduces the hydrolysis rate ${ }^{1}$.

In order to study the sol-to-gel evolution we focused our FTIR study on the observation of both the $\mathrm{Si}-\mathrm{O}(\mathrm{H})$ stretching band at around $950 \mathrm{~cm}^{-1}$ and the $\mathrm{Si}-\mathrm{O}(-\mathrm{Si})$ stretching band between $1040 \mathrm{~cm}^{-1}$ to $1200 \mathrm{~cm}^{-16,7,8,12,13}$.

The first band was deconvoluted in two peaks, a major one at approximately $950 \mathrm{~cm}^{-1}$, due to $\mathrm{Si}-\mathrm{O}(\mathrm{H})$ bond stretching vibration ${ }^{6-8,14}$, and a smaller one at around $915 \mathrm{~cm}^{-1}$, associated to non-bridging free broken $\mathrm{Si}_{-}^{-}$ bonds ${ }^{8,9,14,15}$. The evolution of the peak at around $950 \mathrm{~cm}^{-1}$ with time was followed for all sols (Fig. 3). The wavenumber of the $\mathrm{Si}-\mathrm{O}(\mathrm{H})$ bond vibration increases with the strength of the bond and the degree of connection in the $\mathrm{sol}^{8}$. One can observe in Fig. 4 that whereas the curve corresponding to sol A has a simple asymptotic evolution, a plateau is observed for sols containing formamide. We thus concluded that in the presence of this DCCA, polymerization goes through a temporary stabilization of oligomers, which can explain the non-variation of the $\mathrm{Si}-\mathrm{O}(\mathrm{H})$

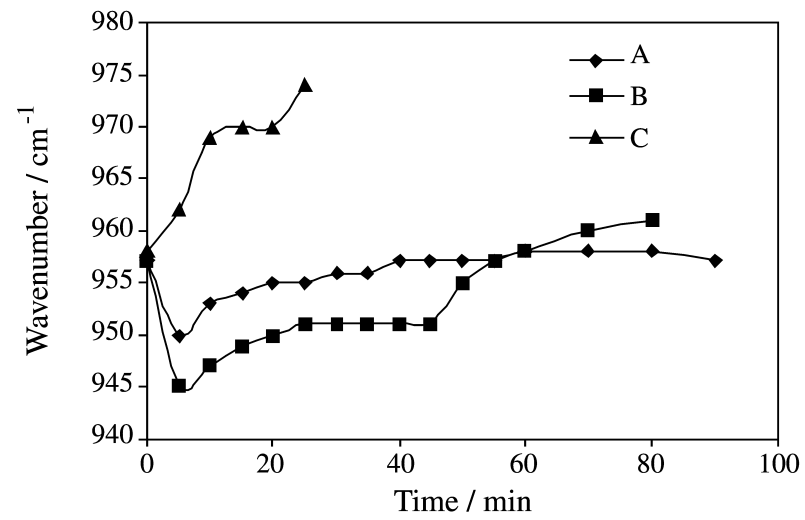

Figure 3. Time evolution of the position of the $950 \mathrm{~cm}^{-1}$ infrared peak. The error values are smaller than $5 \%$.

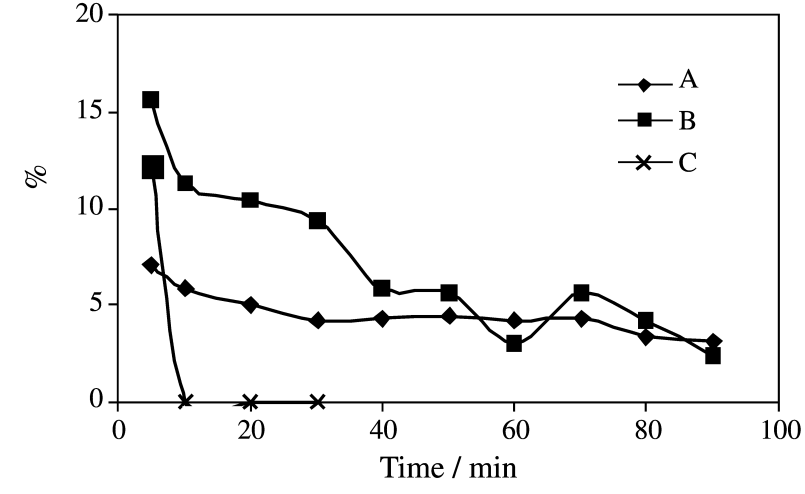

Figure 4. Time evolution of the proportion of the $915 \mathrm{~cm}^{-1}$ infrared peak in the resulting $950 \mathrm{~cm}^{-1}$ band area. The error values are smaller than $5 \%$.

bond wavenumber for a certain time. Viart et al. ${ }^{8}$ related similar results in the system TMOS-water-methanol-formamide. The sols containing formamide evolve towards higher values of this wavenumber. The higher values for sols with formamide shows that the $\mathrm{Si}-\mathrm{O}(\mathrm{H})$ bonds are stronger and belong to a more cross-linked structure. It is more pronounced for sol containing also HF, which reach high values of wavenumber of the $\mathrm{Si}-\mathrm{O}(\mathrm{H})$ bond in very short time.

The peak at about $915 \mathrm{~cm}^{-1}$ gives information on the size of the Si-based species, since it is observed only an average size of clusters, which is smaller than the dimension of $(\mathrm{SiO})_{6}$ rings $^{8,15}$. This is explained by the strong decreasing in the possibility of forming free broken bonds in larger clusters $^{1,8,15}$. Figure 4 presents the time evolution of the proportion of the $915 \mathrm{~cm}^{-1}$ peak area in the resulting band at $950 \mathrm{~cm}^{-1}$ for the sols. One can observe that that the proportion of oligomers containing less than $6 \mathrm{Si}$ atoms noticeably decreases in all sols with time. Thus we concluded that in all sols studied in this work, polymerization goes through a stage where particles are small enough to allow the formation of $\mathrm{Si}-\mathrm{O}$ free broken bonds and give absorption at $915 \mathrm{~cm}^{-1}$ band. With time, these small oligomers then condense together leading to a rapid decrease of the $915 \mathrm{~cm}^{-1}$ peak absorption. It can be noted that this peak area is more important and remains longer present for sol B that contain formamide. It is interesting to notice that, for sol B, the time during which small oligomers remain present coincides with the time of the plateau present in Fig. 3. Sol C presents these oligomers only before $10 \mathrm{~min}$ of reaction. After this time these oligomers condense together with a very rapid decrease of the $915 \mathrm{~cm}^{-1}$ area and a strong increase in the $\mathrm{Si}-\mathrm{O}(\mathrm{H})$ peak wavenumber.

The $\mathrm{Si}-\mathrm{O}-(\mathrm{Si})$ stretching vibration band can be deconvoluted in four or five peaks at around $1040 \mathrm{~cm}^{-1}$, $1080 \mathrm{~cm}^{-1}, 1100 \mathrm{~cm}^{-1}, 1160 \mathrm{~cm}^{-1}$ and $1200 \mathrm{~cm}^{-1}$. Although infrared spectra of silica systems have been extensively 
recorded, the lower frequency features have seldom been discussed and there is no agreement as to the exact structural significance of the peaks occurring between $1000 \mathrm{~cm}^{-1}$ and $1260 \mathrm{~cm}^{-1}$. Though these features are generally accepted to arise mostly from asymmetric stretching vibrations of Si-O-Si bridging sequences, different interpretations still hold ${ }^{15}$. The $1080 \mathrm{~cm}^{-1}$ and $1200 \mathrm{~cm}^{-1}$ peaks, according to literature ${ }^{7,8,15}$, correspond respectively to transversal optical and longitudinal optical asymmetric stretching modes of $\mathrm{Si}-\mathrm{O}-(\mathrm{Si}), \mathrm{AS}_{1} \mathrm{TO}$ and $\mathrm{AS}_{1} \mathrm{LO}$ modes, as observed in vitreous silica. The structure of vitreous silica consists of an assembly of Si-O-Si rings of various sizes in which each $\mathrm{Si}-\mathrm{O}-\mathrm{Si}$ belongs to a cyclic structure. It is reported that silica-gel is formed with cyclic and linear structures ${ }^{1}$. In this work we assigned that the $1080 \mathrm{~cm}^{-1}$ and $1200 \mathrm{~cm}^{-1}$ vibrations of $\mathrm{Si}-\mathrm{O}-(\mathrm{Si})$ bonds belongs to cyclic structures ${ }^{1,7,8,12}$. The other peaks, $1040 \mathrm{~cm}^{-1}, 1100 \mathrm{~cm}^{-1}$ and $1160 \mathrm{~cm}^{-1}$, are assigned to stretching vibrations of Si-O(Si), belonging to a more linear and less cross-linked structure ${ }^{8,15}$. The $1040 \mathrm{~cm}^{-1}, 1080 \mathrm{~cm}^{-1}, 1100 \mathrm{~cm}^{-1}$ and 1160 $\mathrm{cm}^{-1}$ peaks appear as soon as the condensation takes place in the systems studied, whereas the $1200 \mathrm{~cm}^{-1}$ peak appears after several minutes of reaction and it is present only in the spectra of gels containing formamide. The $1040 \mathrm{~cm}^{-1}$ and $1080 \mathrm{~cm}^{-1}$ peaks are partially superimposed by the $1048 \mathrm{~cm}^{-1}$ and $1075 \mathrm{~cm}^{-1}$ peaks due to stretching vibration of $\mathrm{C}-\mathrm{O}(\mathrm{H})$ belonging to ethanol. Thus, we subtract the ethanol spectrum from the spectra of sols. Figure 5 shows the ratio between the intensity of $1040 \mathrm{~cm}^{-1}$ and $1080 \mathrm{~cm}^{-1}$ peaks. It can be observed that the intensity of $1080 \mathrm{~cm}^{-1}$ peak, which belongs to a more branched structure, in relation to $1040 \mathrm{~cm}^{-1}$ peak, belongs to more linear structure, increases after about $40 \mathrm{~min}$ for sol $\mathrm{B}$, whereas it stays roughly constant for sol without formamide. The spectra of sol $\mathrm{C}$ could not be well resolved because its high viscosity after 20 min of reaction. We thus concluded that the struc-

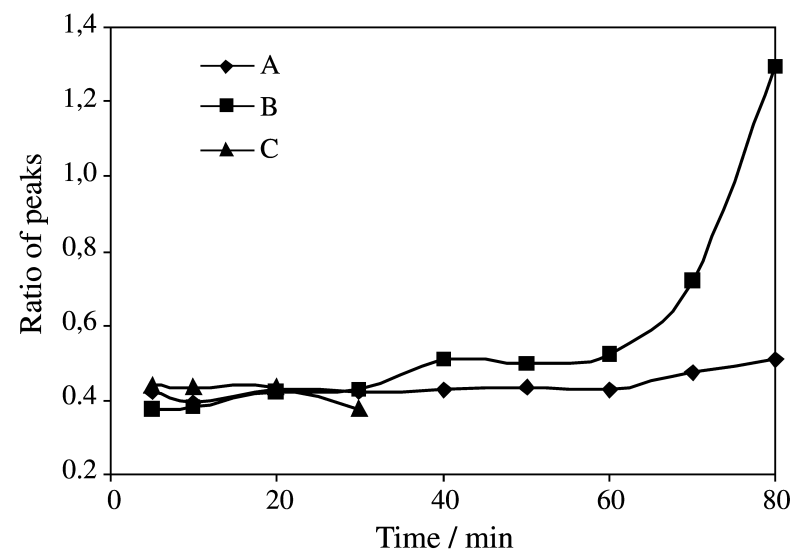

Figure 5. Time evolution of ratio between $1080 \mathrm{~cm}^{-1}$ and $1040 \mathrm{~cm}^{-1}$ infrared peaks. The error values are smaller than $5 \%$.
Table 1. Time of gelation of sols at room temperature and at $40^{\circ} \mathrm{C}$.

\begin{tabular}{lcc}
\hline Sol & Tgel (h) $25^{\circ} \mathrm{C}$ & $\operatorname{Tgel}(\mathrm{h}) 40{ }^{\circ} \mathrm{C}$ \\
\hline A & $572 \pm 5$ & $2 \pm 0.1$ \\
B & $22 \pm 1$ & $1 \pm 0.1$ \\
C & $0.9 \pm 0.1$ & $0.5 \pm 0.05$ \\
\hline
\end{tabular}

ture of the sols containing formamide evolves towards the cross-linked structure of vitreous silica, and the sol A evolves to a more linear structure.

Table 1 presents the time of gelation for sols at room temperature and $40{ }^{\circ} \mathrm{C}$. It can be noted that formamide has a drastic effect on the gelation process for these systems. Sol C, that also contains hydrofluoric acid, presents a shorter time of gelation. It is well known that $\mathrm{F}^{-}$has a high effectiveness in polymerization reactions, mainly due to its smaller ionic radius, versus that of the hydroxyl and that it performs the same function of temporarily increasing the coordination number of silicon. This ability to form five-coordinate transition state leads to more reactive silicon species, which can react faster with additional silanol groups, resulting in an acceleration of the rate of polymerization ${ }^{1,16,17}$.

Formamide, a protic solvent, is capable of forming significantly stronger hydrogen bonds to the reactant species and, compared to ethanol, formamide provides more extensive steric shielding around silicon preventing efficient condensation. This line of reasoning appears inconsistent with the results of this work, which shows more extensive condensation in the formamide system. This contradiction may be explained by the partial hydrolysis of formamide to produce ammonia and formic acid.

$$
\mathrm{HCONH}_{2} \rightarrow \mathrm{HCOO}^{-} \mathrm{NH}_{4}{ }^{+} \rightarrow \mathrm{HCOOH}+\mathrm{NH}_{3}
$$

These reactions lead to a progressive increase of the solution $\mathrm{pH}$ with time, as can be observed in Fig. 6. Because

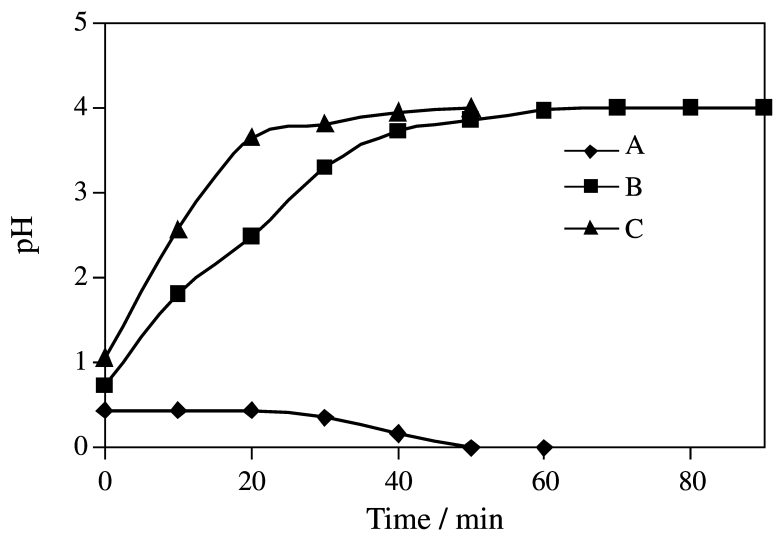

Figure 6. Time evolution of $\mathrm{pH}$ of sols. 
Table 2. Structural properties of silica gels.

\begin{tabular}{llll}
\hline Sol & $\mathrm{S}_{\mathrm{p}}\left(\mathrm{m}^{2} / \mathrm{g}\right)$ & $\mathrm{V}_{\mathrm{p}}\left(\mathrm{cm}^{3} / \mathrm{g}\right)$ & $\mathrm{R}_{\mathrm{p}}(\mathrm{nm})$ \\
\hline A & $695 \pm 35$ & $0.42 \pm 0.02$ & $1.2 \pm 0.06$ \\
B & $465 \pm 23$ & $1.13 \pm 0.05$ & $4.9 \pm 0.2$ \\
C & $243 \pm 12$ & $0.37 \pm 0.02$ & $6.3 \pm 0.3$ \\
\hline
\end{tabular}

base-catalyzed silanol condensation is generally observed to be first-order in $\left[\mathrm{OH}^{-}\right]^{1}$, ammonia should increase the condensation rate. At $\mathrm{pH} \sim 4$, the solubility of silica and the dissolution rate are quite low. Therefore, an effect of formamide additions may be to strengthen the gel by maximizing the extent of condensation without reorganization into a particular structure. This is consistent with observations that formamide increases the microhardness of wet gels and correspondingly the pore size of dried gels, while maintaining a high surface area and large pore volume ${ }^{1,18}$. The values of structural properties such as specific surface area $\left(S_{p}\right)$, specific pore volume $\left(v_{p}\right)$ and average pore radius $\left(R_{p}\right)$ for the silica gels heated to $400{ }^{\circ} \mathrm{C}$ obtained in this work are listed in Table 2. It can be seen that sol $\mathrm{A}$ has a fine pore structure, whereas sols B and C present coarser structure. These structural evolutions are consistent with the kinetic models of aggregation found in literature ${ }^{1}$ : acidic in sol A, evolving in a cluster-cluster aggregation, leading to more linear structure and basic for sols $\mathrm{B}$ and $\mathrm{C}$, evolving in a monomer-cluster aggregation, leading to a more branched network $^{1,8}$.

\section{Conclusions}

The kinetic of hydrolysis and polycondensation of silica-gel systems are affected by formamide. This additive hydrolysis during reactions, increasing the $\mathrm{pH}$ of solutions and changing the mechanism of hydrolysis and condensation. In the absence of formamide, the sol structure is poorly interconnected and the gel evolves to a microporous material. For sols containing formamide, a two-step structural evolution was observed. Condensation leads to small oligomers that condense together in a more cross-linked structure, resulting in mesoporous materials. This effect is more pronounced for systems with $\mathrm{F}^{-}$.

\section{Acknowledgement}

The authors thank the financial support by CAPES and CNPQ

\section{References}

1. Brinker, C.J.; Scherer, G.W. Sol-Gel Science: The Physics and Chemistry of Sol-Gel Processing, Academic Press, inc. San Diego, CA., p. 907, 1990.

2.deLange, R.S.A.; Hehhink, J.H.A.; Kelzer, K.; Burggraaf, A.J. Journal of Non-Crystalline Solids, v. 191, p. 1, 1995.

3.Lenza, R.F.S.; Vasconcelos, W. L. Materials Research, v. 2, n. 3, p. 197, 1999.

4. Winter, R.; Chan, J.B.; Frattini, R.; Jonas, J. Journal of Non-Crystalline Solids, v. 105, p. 214, 1988.

5.Sol-Gel Chemistry. http:// www.psrc.usm.edu/ mauritz/solgel.htm. 7/29/1999.

6.Schraml-Marth, M.; Walther, K.L.; Wokan, A.; Handy, B.E.; Baiker, A. Journal of Non-Crystalline Solids, v. 143, p. 93, 1992.

7. Orcel, G.; Phalippou, J.; Hench, L.L. Journal of NonCrystalline Solids, v. 88, p. 114, 1986.

8. Viart, N.; Niznansky, D.; Rehspringer, J.L. Journal of Sol-Gel Scince and. Technology, v. 8, p. 183, 1997.

9. Sugahara, Y.; Okada, S.; Sato, S.; Kuroda, K; Kato, C. Journal of Non-Crystalline Solids, v. 167, p. 21, 1994.

10. Voon Ng, L.; McCormick, A.V. Journal of. Physic Chemistry, v. 100, p. 12517, 1996.

11. Ferreira, M.P. Caracterização Estrutural de Géis de Sílica Durante as Etapas Iniciais de Gelação e Secagem. Dissertação de Mestrado, Universidade Federal de Minas Gerais, 146 p., 1996.

12. Hench, L.L.; West, J.K. Chemical Review, v. 90, p. 33, 1990.

13. Inokama, L.H.; Kurata, Y.; Hasegawa, S. Journal of Non-Crystalline Solids, v. 185, p. 249, 1995.

14.Lenza, R.F.S.; Vasconcelos, W.L. Ceramica, submitted for publication.

15. Almeida, R. M.; Pantano, C.G. Journal of Applied Physics, v. 68, n. 8, p. 4225, 1990.

16. Iller, R.K. The Chemistry of Silica, John Wiley ed., New York, 1979.

17.Lenza, R.F.S.; Vasconcelos, W.L. Journal of NonCrystalline Solids, in press.

18. Orcel, G.; Hench, L.L; Artaki, I.; Jonas, J.; Zerda, T.W. Journal of Non-Crystalline Solids, v. 105, p. 223, 1988. 